\title{
Book review: Contemporary Lithic Analysis in the Southeast: Problems, Solutions, and Interpretations
}

\author{
John Edward Dockall
}

Prewitt and Associates, Inc. 2105 Donley Drive, Suite 400, Austin, Texas, United States.

Email: Jdockall@paiarch.com

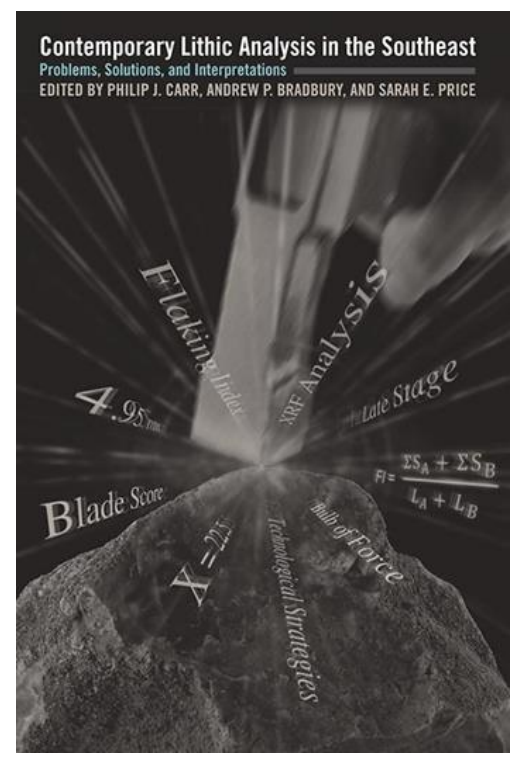

Contemporary Lithic Analysis in the Southeast: Problems, Solutions, and Interpretations Edited by Philip J. Carr, Andrew P. Bradbury, and Sara E. Price

The University of Alabama Press, Tuscaloosa. 2012, pp. 253. ISBN 978-0-8173-5699-6

http://www.uapress.ua.edu/product/Contemporary-Lithic-Analysis-in-the-Southeast,5318.aspx

This volume represents the outgrowth of practical and theoretical research in lithic analysis in the southeastern United States. Although the papers are regionally specific, the examples and methods used provide ample reason for lithic analysts and interested archaeologists in any region to acquire a copy. The text is organized into thirteen chapters on topics of the individual author's choosing with the caveat that all papers relate to lithic research and analysis in the greater southeastern United States. The editors placed no theoretical or methodological constraints upon the contributors. Each paper follows an organization of technology approach in method and interpretation.

The editors provide the reader with a less-than-favorable critique of the then current state of affairs in stone tool research in the Southeast. Carr, Bradbury, and Price noted a

Published by the School of History, Classics and Archaeology, University of Edinburgh ISSN: 2055-0472. URL: http://journals.ed.ac.uk/lithicstudies/

This work is licensed under a Creative Commons Attribution 2.5 UK: Scotland License. 
decades long lack of concern for theoretical innovation, integration of data, and methodological advances in the region concerning stone tool research. They then provide an excellent discussion of the organization of technology approach. Organization of technology incorporates the entire sequence of procurement, manufacture, use, reuse, and discard of stone tools and places these behaviors within the greater contexts of environment, social and economic strategies and cultural choices. The overall approach and concept of organization of technology is similar to the chaîne opératoire concept applied commonly by lithic analysts in European countries (see Soressi \& Geneste 2011). The editors note a significant lack of meaningful data among lithic studies in the Southeast.

The editors identify two themes among the selected papers: classification bias and organization of technology. Papers on recovery and classification bias include those by Price, Sain and Goodyear, Pevny, Potts, and Edmonds. Price and Edmonds address recovery bias and interpretive difficulties in terms of screen size used during fieldwork. Pevny addresses artifact and assemblage-level taphonomic bias at the Gault site. Bradbury and Carr examine the differences of inter-observer differences in the identification of blades and bipolar cores and flakes. Sain and Goodyear develop and discuss a measurement technique to distinguish between true blades and blade-like flakes and how different Clovis blade making was in the Southeast compared to the Southwest and elsewhere. Finally, Potts considers classification errors resulting from differences in raw material such as low-quality quartz and better qualities of chert and noted that classification errors were higher among low quality raw materials.

For the second theme of organization of technology, authors relate technological observations and analytical techniques to interpretations of stone tool-related behaviors, raw material provisioning or aspects of tool manufacture. Miller and Smallwood develop a bifacethinning index for analysis of bifaces from Clovis contexts at the Topper site and determine that discrete stages of biface manufacture are difficult to isolate. They argue for a continuum approach to biface manufacture and identified discrete areas of the site where certain parts of the continuum of biface manufacture occurred. Authors Cooper and Thacker (and co-authors) examine the influences of mobility and settlement on raw material procurement, use, and provisioning among Archaic lithic assemblages. They noted that mobility differences among groups and raw material procurement strategies directly influenced the lithic technology. Franklin (and co-authors) provide a useful application of the organization of technology approach to the assemblage from Eagle Drink Bluff shelter in Tennessee. The authors employ both the organization of technology and the chaîne opératoire concept..

The final chapters are authored by William Andrefsky, Jr, and George H. Odell. Each author place his own unique perspective upon the papers and place them into broader contexts for the Southeast and lithic studies as a viable research area. Andrefsky delves deeper into a comparison/contrast between the organization of technology approach and the chaine opératoire concept that will be interesting for lithic analysts working on non-North American lithic assemblages. Odell's chapter provides a fitting end for the book as it was published after his death and is dedicated to his memory. Both authors remain optimistic regarding the future status of lithic analysis in the Southeast.

\section{References}

Soressi, M. \& Geneste, J.-M. 2011, The History and Efficacy of the Chaîne Opératoire Approach to Lithic Analysis: Studying Techniques to Reveal Past Societies in an Evolutionary Perspective. Paleo Anthropology, 2011: 334-350. doi:10.4207/PA.2011.ART63 